\title{
Virus-Like Particles as an Instrument of Vaccine Production
}

\author{
B. V. Syomin ${ }^{a, *}$ and Y. V. Ilyin ${ }^{b}$ \\ ${ }^{a}$ Institute for Statistical Studies and Economics of Knowledge (ISSEK), \\ National Research University Higher School of Economics, Moscow, 101000 Russia \\ ${ }^{b}$ Engelhardt Institute of Molecular Biology, Russian Academy of Sciences, Moscow, 119991 Russia \\ *e-mail: bsyomin@hse.ru \\ Received September 28, 2018; revised December 19, 2018; accepted December 24, 2018
}

\begin{abstract}
The paper discusses the techniques which are currently implemented for vaccine production based on virus-like particles (VLPs). The factors which determine the characteristics of VLP monomers assembly are provided in detail. Analysis of the literature demonstrates that the development of the techniques of VLP production and immobilization of target antigens on their surface have led to the development of universal platforms which make it possible for virtually any known antigen to be exposed on the particle surface in a highly concentrated form. As a result, the focus of attention has shifted from the approaches to VLP production to the development of a precise interface between the organism's immune system and the peptides inducing a strong immune response to pathogens or the organism's own pathological cells. Immunome-specified methods for vaccine design and the prospects of immunoprophylaxis are discussed. Certain examples of vaccines against viral diseases and cancers are considered.
\end{abstract}

Keywords: vaccines, vaccinomics, immunome, nanoparticles, virus-like particles

DOI: $10.1134 / \mathrm{S} 0026893319030154$

\section{INTRODUCTION}

Immunoprophylaxis has long been used to control infectious diseases exerting an enormous impact not only on the global health but also on the safety of numerous populations of agricultural animals. In the past decades, the focus on vaccine production technologies has changed from handling intact pathogens to producing recombinant subunit vaccines based on isolated target antigens [1]. Intensive development of recombinant vaccines began in the 1980s when it became possible to clone the desired DNA sequences into expression plasmids and produce the target proteins. The construction of a recombinant vaccine takes advantage of the knowledge of the nucleotide sequences of genes encoded by a pathogen, and involves identification of the antigenic determinant, synthesis of the nucleotide sequence encoding the antigen, its cloning into an expression vector, and production of the target peptide in a certain expression system. The expression systems for individual heterologous proteins has been developed based on the prokaryotic and eukaryotic cells, which allow us to produce target proteins both on laboratory and industrial scales [2].

The interest in recombinant vaccines is a consequence of the emergence of new infectious diseases, most often zoonotic ones. Among them are the outbreaks of human diseases caused by the Ebola virus,

\footnotetext{
Abbreviations: VLP, virus-like particles.
}

Zika virus, Marburg virus, the Middle East respiratory syndrome, and severe acute respiratory syndrome coronaviruses [3]. Oncology also places great hopes in recombinant vaccines, which may help to overcome immune tolerance in the case of cancer treatment [4]. Moreover, there exists a constant threat of the emergence of new highly virulent strains of well-known viruses due to unceasing mutational processes in virus genomes [5]. Against this background, a new scientific concept, vaccinomics [6], which consists of identifying the minimum subset of antigens, which are able to induce a competent immune response to a pathogen or tumor by their specific interaction with the $\mathrm{B}$ and $\mathrm{T}$ immune cells, is being actively developed. Using this approach it appears possible to design vaccines based on the minimum subset of antigens which most specifically characterize the pathogen in its interaction with the immunome (the set of all immune receptor sequences, which are present in the individual organism) [7].

Target detection of epitopes, the regions located on the surface of the protein, is possible with the aid of $\mathrm{X}$-ray analysis, which is rather labor-consuming since it requires obtaining protein crystals. Presently, the 3-D protein structure modeling has found broad use. This approach is based on identification of the physicochemical and electrostatic characteristics of the polypeptide chain regions and correlation of these characteristics with antigenic properties. Two strategies are currently utilized, namely, modeling by homology and 
de novo modeling. In the first case, the Protein Data Bank (http://www.ncbi.nlm.nih.qov/genbank/) database of 3-D protein structures is used to model the protein. The commonly used MODELLER [8], as well as other software such as I-TASSER [9], SWISS-MODEL [10], EsyPred3D [11], 3D-JIGSAW [12], Phyre [13], and CPHmodels [14], can be used as homology modeling tools. The limitation of this approach lies in the requirement that the structures of homologous proteins should demonstrate more than $30 \%$ identicality [15]. The de novo modeling strategy is based on the computer simulation of the protein folding process (Rosetta [16] and TASSER [17] software). In this case, all possible variants of polypeptide chain folding are considered, and the most energetically favorable conformation, i.e., the one with the lowest potential energy, is chosen.

Predicted antigenic determinants are synthesized using genetic engineering vector techniques and heterologous protein expression systems, and then are experimentally tested using, for example, the antibody neutralization assay. Using protein expression systems it is possible to produce virus-like particles (VLPs), which are made up of monomers, which are able to multimerize into VLPs, and display the antigenic determinants of target pathogens on their surface. This point will be addressed further in the review, we will just observe here that even complex epitopes represented by trimers may be obtained using heterologous expression systems. This has been demonstrated, for instance, for the trimeres of the human immunodeficiency virus (HIV-1) envelope glycoprotein [18, 19] and influenza virus haemagglutinin [20].

In order to choose the most specific antigens of the pathological agent of a new infectious disease, it appears inevitable to work with the infected material if only to isolate and sequence the nucleic acids containing the genetic information of the pathogen. However, in order to produce a vaccine based on epitopes characteristic for the target pathogen, there is no need to work with the pathogen itself. Therefore, apart from all other advantages of the vaccines of this kind, they appear to be improved in terms of biological safety. Vaccines based on the presentation of a subset of antigenic determinants of the infectious agent are characterized by a high level of reproducibility when commercially manufactured and are highly effective [21], since in this case, the immune response is directed exclusively against the most significant antigenic elements of the pathogenic microorganism or tumor.

\section{PEPTIDES AS PROTECTIVE ANTIGENS}

A number of vaccines specifically interacting with certain immune system receptors have been tested to date. For example, a vaccine containing only a single Epstein-Barr virus epitope specifically recognized by $\mathrm{CD} 8^{+} \mathrm{T}$-cells is proposed for the prophylaxis of mononucleosis in human [22]. This vaccine prevents the development of the disease, although it does not protect the organism from the entry of the virus. Another example is classical swine fever virus (CSFV). It has been demonstrated that the E2 viral protein produced in the baculovirus expression system induces the synthesis of CSFV-neutralizing antibodies in pigs [23].

Vaccines are designed to produce immunity to a disease. Although a single epitope is able to induce a strong immune response, it appears usually insufficient to induce protective immunity. The in vitro synthesized peptide properly representing the main antigenic determinant of the pathogen is highly likely not to be itself a strong immunogene primarily because of its small size $(<10 \mathrm{~nm})$ and high risk of proteolytic degradation. This problem may be overcome by the use of nanoparticles. It has been shown in a considerable number of works that in order to induce a strong immune response, antigenic determinants should be exposed on the surface of nanoparticles whose shape and size (20-150 nm) mimic those of the virus (Fig. 1). In this respect also, VLPs, the nanoparticles composed by viral proteins capable of self-assembly (multimerization) into structures morphologically resembling viruses, are the choice selection for the role of a strong immunogene. Antigenic determinants multiply repeatedly on the VLP surface and promote complement fixation and B-lymphocyte receptor clusterization leading to the activation of the immune response. Additionally, the same antigen multiply displayed on the surface of the particle promotes the multiplication of the pool of autoreactive B-cells, which is the primary objective when designing vaccines against autoimmune diseases and tumors [29].

\section{NATURAL SOURCES FOR VLP BIOENGINEERING AND THE SPECIFIC FEATURES OF THEIR ASSEMBLY}

Structural proteins of various viruses are capable of autonomous self-assembly into VLPs. They interact with the formation of globular, icosahedral, or rodlike structures. So far, the structural proteins of several dozen viruses have been obtained in heterologous expression systems, and almost all of them proved able to form VLPs. The VLP size varies from 20 to $200 \mathrm{~nm}$ and is similar to the size of the corresponding viruses [30]. Being similar to viruses allows VLPs to penetrate into the lymph and to be efficiently entrapped by antigenpresenting cells [31].

Currently, several heterologous expression systems and the corresponding expression vectors which can be used with them are available. These systems are based on both the bacterial cells (the pET system based on Escherichia coli cells is often exploited) and different eukaryotic cells. In the case of eukaryotic cells, the most commonly used systems are yeast expression systems and the ones which rely on Drosophila [32] and Spodoptera frugiperda insect cell lines [33]. Mammalian cells are also utilized, the most pop- 


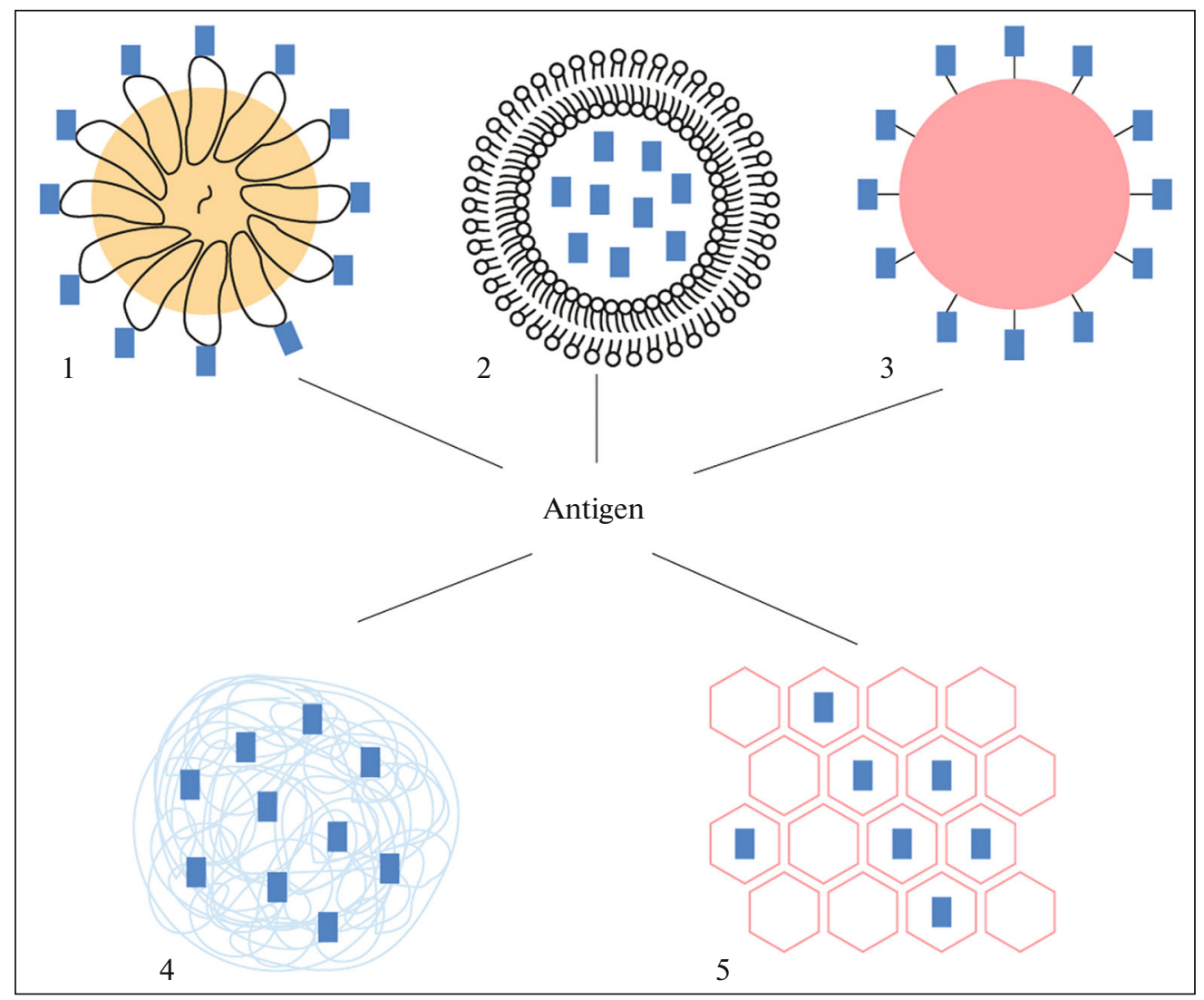

Fig. 1. Schematic representation of main types of nanoparticles used for vaccine production: (1) VLPs, (2) liposome-based particles [24], (3) nondegradable spherical nanoparticles (for example, metal nanoparticles) [25], (4) polymer nanoparticles [26], (5) graphene nanosheets [27] and nanotubes [28].

ular among them being CHO and HEK293 [34]. The cost of heterologous protein production in bacterial systems is lower than in eukaryotic cells. However, when studying the functional activity of the protein or VLP associated, for example, with the potential glycosylation sites or interaction with ubiquitin, or other ubiquitin-like peptides [35], no alternative to eukaryotic expression systems is available. It should be noted that the choice of the expression system is up to the researcher and is driven by the research task. For example, in different laboratories different eukaryotic systems for viral protein expression, including plant cells, are used to produce VLPs which are used for vaccination against the hepatitis $\mathrm{C}$ virus (HCV) [36].

In most cases, VLPs assembled from a virus protein are considered as a candidate vaccine against this very virus, since protein monomers in multimeric configuration (VLP) induce a more potent immune response than protein monomers [29, 30]. The strong immunogenic properties of VLPs are determined by several factors. First of all, the dominant epitope of the structural protein is displayed as a part of the particle and is present in a multimeric form as is the case with a native virion [21]. Second, VLPs stimulate B-lymphocytes and induce T-lymphocytes in the same manner as does the virus infecting the host organism [30]. For example, VLPs formed by the main capsid protein L1 of the human papilloma virus of several serotypes are successfully used as vaccines against cervical cancer [37]. A vaccine against hepatitis B virus has been produced which contains VLPs in the lipid membrane envelope [38]. The vaccine against coxsackievirus A6 contains VLPs assembled from the virus capsid proteins produced in the baculovirus expression system [39]. Scientists from China [40] have demonstrated that the capsid protein (VP60) of the rabbit hemorrhagic disease virus (RHDV) efficiently multimerize into VLPs, and a single intramuscular injection of the obtained VLP preparation completely protects the immunized rabbits against RHDV infection for at least 180 days. The porcine circovirus capsid protein is also able to efficiently assemble into VLPs when synthesized either in the human embryonic kidney cell culture (HEK293) [41], or yeast [42] and baculovirus [43] expression systems, as well as in bacteria [44]. Footand-mouth disease VLPs are assembled from three structural polypeptides VP0, VP1, and VP3 (naturally produced as a result of processing the $\mathrm{P} 1-2 \mathrm{~A}$ precursor polypeptide), simultaneously produced in E. coli [45]. It has been recently demonstrated that the polyprotein 
of the duck hepatitis A virus produced in the baculovirus expression system assembles into VLPs immediately in the cultured Spodoptera frugiperda (sf9) cells, while immunization of ducklings with the obtained VLPs induces a high level humoral immune response and protects them from developing the disease [46]. The abilities of VLPs resulting from multimerization of the cloned virus protein to play the role of an immunogen are not limited just to the presentation of their proper epitopes but may also be taken advantage of to display heterologous proteins.

Multimerization of capsid proteins into a particle requires the presence of nucleic acid, while for in vitro assembly, a short oligonucleotide (7-10 nt) is sufficient [47]. Therefore, VPLs formed by capsid proteins are free from the infectious virus RNA or DNA. Moreover, the above-mentioned property, which triggers protein monomer multimerization by nucleic acid, may be taken advantage of to package RNA or DNA into a particle with two different objectives. Hence, antisense RNA can be used to suppress virus expression. For example, in the case of the vaccine against foot-and-mouth disease, researchers from China [48] not only displayed the VP1 epitope of the foot-and-mouth disease virus on the surface of VLPs but also packaged the antisense RNA complementary to the fragment of the viral genomic RNA into a particle.

Another goal of nucleic acid packaging into a particle lies in the presentation of viral nucleic acids leading to the activation of specific immune receptors which induce the synthesis of type I interferons (INF) and other cytokines triggering the antivirus response [49]. It has been demonstrated that long DNA and RNA molecules may be incorporated into VLPs. For example, mRNA for the reporter protein, red fluorescent protein, was packaged into particles representing the hepatitis E capsids [50]. The plasmid containing the green fluorescent protein (GFP) gene was encapsidated into the VLPs assembled in vitro from the main capsid protein of the hamster polyoma virus [51]. A strategy for the packaging of up to $17 \mathrm{kbp}$ doublestranded circular DNA into the particles was developed using the structural protein of the SV40 simian retrovirus expressed in baculovirus system [52].

There exist two fundamentally different approaches for nucleic acid incorporation into VLPs: (1) in vitro VLP assembly from protein monomers in the presence of RNA or DNA, which is to be encapsidated into the VLP; (2) exposure of the assembled VLPs to osmotic shock in the presence of nucleic acids. Osmotic shock is produced by using a solution with a low ionic strength; nucleic acid enters into a VLP as a result of the shift in the surface structures [53]. However, the incubation of VLPs in the presence of nucleic acids without exposure to osmotic stress results in a certain part of the nucleic acids becoming associated with the particles [54]. A far more predictable approach is the in vitro assembly of VLPs from the mixture of protein monomers and nucleic acids which should be encapsidated in them. In this case, after synthesis in a heterologous system, the obtained protein monomers are purified to completely remove the contaminating nucleic acids from the protein preparation; then the proteins are denatured in 7-8 $\mathrm{M}$ urea, nucleic acids which should be packaged are added, and the proteins are assembled into the particles by eliminating urea from the solution. The use of this strategy was demonstrated, for instance, in the works [47, 55, 56].

Protein association into a particle is a reversible process. VLP dissociation can be easily achieved by the addition of a denaturing agent. Further, it may be removed and VLPs may be reassembled in vitro [47] with the encapsidation of the target RNA or DNA into the particle. This approach was implemented for the P21 protein of the hepatitis B virus. Virus proteins produced in the heterologous expression system were denatured in $7 \mathrm{M}$ urea solution, and their assembly into VLPs in the presence of the nucleic acid was further induced [57].

Protective immunity is controlled by specific humoral and cellular mechanisms activated by the antigen. Posttranslational protein modifications and covalent bonds between the modifying molecules and the functional groups in the polypeptide chains are of great importance for immune homeostasis during the antiviral response. The balance between phosphorylation, ubiquitination, methylation, acetylation, SUMOylation, ADP-ribosylation, and glutamilation of a certain antigen performs the fine adjustment of the host's antiviral response $[49,58]$. The structural proteins for VLP production when synthesized in the eukaryotic expression systems undergo a number of posttranslational modifications. In particular, the Gag gypsy monomer proved to be a natural substrate for type 2 casein kinase [59]. Moreover, while produced in the eukaryotic cell, Gag gypsy monomers become associated with ubiquitin and SUMO, the cellular protein partners of the viral structural protein [33].

Generally, ubiquitin and SUMO can bind with any lysine residue within the protein molecule, although there are preferable binding sites; it should also be noted that phosphorylation determines which of these two partners binds with the protein $[60,61]$. Additionally, binding with a limited number of the above-mentioned signal peptides, such as monoubiquitination [62], usually plays a regulatory role and controls the transport of the protein itself, or the particle formed by it. In the case of polyubiquitination, the protein is destined for proteasome degradation $[60,63]$.

\section{RECOMBINANT VLPS FOR PRESENTATION OF FOREIGN ANTIGENIC DETERMINANTS}

By constructing recombinant polypeptides based on the viral capsid proteins it is possible to obtain VLPs bearing several antigens. For example, DNA encoding 
the VP2 capsid protein of the porcine parvovirus was fused with the DNA fragment encoding 35 amino acid residues of the main antigen of porcine circovirus (PCV2) nucleoprotein. The resulting hybrid DNA was used to produce protein in heterologous cells which further formed VLPs. These VLPs induced a significantly stronger immune response against PCV2 than the recombinant adenovirus encoding the open reading frame 2 (ORF2) of PCV2 [41]. Another interesting example is represented by the VLPs formed by the influenza virus matrix protein and displaying a Toxoplasma gondii antigen on their surface [64]. There exists another approach to designing therapeutic vaccines based on VLPs. In this case, the VLP surface displays the variable fragment of an antibody specific to the antigen of the target virus [65]. Moreover, knowing which receptor is bound by the virus proteins renders it possible to produce particles possessing tropism to the cells of certain tissues. For example, the pre-Sprotein of the hepatitis $B$ virus exposed as a ligand on the VLP surface provided for their specific binding with hepatocytes [66].

VLPs assembled from the structural proteins of bacteriophages are also considered as carriers for human and animal vaccine production. For example, the DNA fragment encoding foreign protein was inserted into the DNA region encoding the $\mathrm{N}$-terminal $\beta$-hairpin of the coat protein of the $E$. coli MS2 phage. It has been demonstrated that the expression of the obtained construct in bacterial cells resulted in the production of the recombinant protein in which a foreign peptide was present in the central part of the hairpin. The obtained chimeric protein monomers were able to self-assemble into particles morphologically similar to the phage capsid both in vivo and in vitro [67]. Using the mentioned property of the MS2 coat protein, VLPs displaying the EP141-160 epitope of the foot-and-mouth disease VP1 structural protein on their surface were obtained. These chimeric VLPs induced string immune response in the animals, which allowed regarding them as a promising base for the development of a prophylactic vaccine [68]. It is worth noting that the exposure of EP141-160 on the VLP surface resolved a long-standing problem of how to make use of the beneficial properties of this peptide. Researchers from several laboratories have demonstrated that this antigenic determinant of the footand-mouth disease not only induces the production of neutralizing antibodies but also stimulates T-lymphocytes [69]. However, when isolated, EP141-160 is not able to induce the immune response protecting animals against the foot-and-mouth virus infection [70]. Many attempts were made to solve this problem, for example, by combining the antigenic determinant with large molecules, such as for instance, T cell-specific molecules [71]. However, only integration of EP141-160 into VLPs resulted in the possibility of using this antigenic determinant as a strong immunogen for vaccine production [68].
Practically all structural proteins of phages infecting various species of bacteria are able to autonomously form VLPs. For example, Salmonella typhimurium phages are able to autonomously multimerize into VLPs on whose surface the epitopes of eukaryotic viruses, including the epitopes of the human influenza virus may be exposed [72]. At the same time, however, bacteriophages are apparently incapable of presenting large epitopes, whose length exceeds 24 amino acid residues [67].

Structural proteins of retroviruses and retrotransposons have a higher capacity compared to bacteriophage proteins. This means that protein monomers forming the particle may be fused with a longer peptide and still retain the ability to multimerize. In particular, it has been shown for the Gag gypsy capsid protein [73], that at least $26 \%$ of its amino acid sequence (more than 100 amino acid residues) is of little importance for multimerization into VLPs [55]. Therefore, the truncated form of this protein may be fused with a heterologous peptide with the length similar to the length of the deleted fragments and a recombinant protein may be obtained which will retain its ability to self-assemble into VLPs. In such a way, the truncated Gag gypsy fused with the heterologous peptide formed particles when it was synthesized in bacterial cells. We were also able to assemble particles from the purified protein monomers in vitro $[47,55,74]$. The obtained particles resembled the native gypsy virus by their morphology [75]. The substitution of the deleted region in the DNA encoding Gag gypsy by the nucleotide sequence encoding the main antigenic determinant of the foot-and-mouth virus VP1 protein (EP141-160) and $\mathrm{His}_{6}$-tag resulted in the formation of particles which displayed EP141-160 as the target antigen. The advantage of the technique used is that VLPs formed by the protein containing $\mathrm{His}_{6}$-tag can be readily isolated and purified by affinity chromatography [76].

Chimeric VLPs may be obtained through the construction of recombinant DNA molecules encoding both the corresponding virus protein and a foreign peptide or protein. Another way is VLP pseudotyping. This approach was elaborated using the hamster polyomavirus. The V1 capsid protein of this virus first forms pentamers which further assemble into VLPs comprised of 72 pentamers. When V1 is expressed together with the minor capsid protein V2, the latter binds with the central part of each V1 pentamer. It has been demonstrated that the N-terminal part of V2 is not involved in this interaction and therefore may be removed and substituted by the target epitope [77].

Another approach is also known. Antigen is immobilized on the VLP via covalent binding between the reactive groups of the amino acid residues of the antigen and VLP. This approach proved to be ineffective due to the disruption of the native conformation of the antigen attached to the particle surface [77, 78]. This problem was countered in the following way. GlyGly- 
LysGlyGly sequence was inserted into the monomer subunits for VLP assembly. In this environment, the reactive $\varepsilon$-amino group of Lys residue is exposed and ready to interact with the Cys-group of any protein in the presence of the cross-linking agent, such as mMaleimidobenzoyl-N-hydroxysulfosuccinimide ester (Sulfo-MBS) [79], or Succinimidyl-6-[( $\beta$-maleimidopropionamido)hexanoate] (SMPH) [80]. Although the authors claimed that the described system of molecular assembly may be used to induce strong Blymphocyte response against most antigens and prospective vaccine prototypes were suggested, this platform became the prototype only for a single prospective preparation based on VLPs, the medication for lowering blood pressure in patients with hypertension [80], due to the development of the new improved techniques for antigen immobilization of the VLP surface, which will be discussed below.

One of them takes advantage of the ability of $\mathrm{His}_{6}{ }^{-}$ tag to bind with multivalent Tris-nitrilotriacetic acid (trisNTA) which in turn binds with a broad range of molecules, in particular, with biotin. The possibilities of this elegant technique for the functionalization of noninfectious viral nanoparticles were demonstrated in the case of VLPs formed by the norovirus (NoV) structural proteins. Using the baculovirus expression system, the authors obtained NoV VLPs, displaying His $_{6}$-tag on their surface, which was first used to purify VLPs, and further to bind trisNTA molecules conjugated with a fluorescent dye, or biotin which in turn successfully bound streptavidin [81]. Notwithstanding some authors suggesting the described technique to be promising for VLP vaccine production, this approach continues to be only a prototype and has not advanced further than model experiments.

The search for techniques providing efficient and stable immobilization of the antigen on the VLP surface led to the development of a versatile platform which allows us to covalently attach large antigens to the VLP surface [82]. This molecular assembly system uses the tag-catcher conjugation system which was derived from the CnaB2 domain of fibronectin-binding protein $\mathrm{FbaB}$ from Streptococcus pyogenes. As a result a highly reactive SpyTag peptide (13 amino acid residues) was obtained which efficiently interacted with the SpyCatcher protein with the formation of isopeptide bonds in a broad range of buffer solutions [83]. The SpyTag peptide was inserted into the VLP-forming polypeptide of the Acinetobacter-infecting phage (these particles were called AP205), so that each monomer forming AP205 displayed two SpyTag peptides. A recombinant antigen consisting of the target protein and the SpyCatcher peptide was produced using bacterial or baculovirus expression systems [84]. The obtained antigen efficiently bound with the VLP surface and induced a very strong immune response. Almost the same effect was observed in the case of the reverse combination of the conjugating peptides, that is when SpyCatcher was incorporated into VLPs, and SpyTag was fused to the antigen. This system is already utilized to design different types of vaccines, including the vaccines against tuberculosis and malaria $[84,85]$. A recent report has demonstrated that it was successfully used to develop a vaccine against breast cancer [86]. This work is remarkable due to the fact that the high density of the HER2 antigen (human epidermal factor receptor 2) synthesized in the cultured Drosophila melanogaster cells could be obtained on the AP204 VLP surface [32]. The obtained particles induced a strong immune response to the antigen in the patients, which rendered it possible to overcome the immune tolerance to HER2 known for patients with the HER2-dependent breast cancer [85, 86].

In summary, the analysis of the discussed published data allows us to conclude that the nature of the VLP-forming protein is not as important for VLP functionalization as the technique which makes it possible to obtain high antigen density on the surface of VLPs (Table 1).

\section{COMMERCIAL VACCINES BASED ON VLP AND PROSPECTS OF BROADENING THE PRODUCT RANGE}

A number of VLP vaccines are available on pharmaceutical markets in many countries. The most wellknown are the Cervarix ${ }^{\circledR}$ and Gardasil ${ }^{\circledR}$ vaccines against cervical cancer, which have been successfully used for prophylaxis of this disease in girls for more than ten years. Both vaccines are based on VLPs formed by the main capsid protein L1 of the human papilloma virus belonging to several serotypes [37]. Engerix and Recombivax $\mathrm{HB}$ vaccines against the hepatitis B virus representing VLPs enveloped in a lipid membrane [38], as well as Hecolin and Xiamen Innovax vaccines against hepatitis E [88], were developed and commercialized. The anti-malaria vaccine Malaria RTS has been certified, which represents the C-terminal part of the CS protein of Plasmodium falciparum attached to the surface antigen of the hepatitis $\mathrm{B}$ virus (HBsAg), which is also used in the certified vaccines against hepatitis $B$. To stabilize recombinant VLPs, the fused protein is expressed together with the HBsAg protein in Saccharomyces cerevisease [89]. A vaccine against the porcine circovirus representing VLPs assembled from the VP2PCV2 capsid protein synthesized in a heterologous system has also been commercialized [41].

An increasing number of works have appeared that report on the development of vaccines based on nanoparticles, including VLPs and/or replicationinactive viruses. Among the apparent advantages of vaccines of this kind are their high specificity, efficiency, and good pharmacokinetic characteristics. It has been demonstrated that in an organism VLPs reach lymphatic nodes in less than $10 \mathrm{~min}$, while the particle mixture bearing different antigens may be pro- 
Table 1. Examples of universal VLP platforms for antigen presentation

\begin{tabular}{l|l|l}
\hline \multicolumn{1}{c|}{$\begin{array}{c}\text { Strategy of antigen immobilization } \\
\text { on particle surface }\end{array}$} & \multicolumn{1}{c}{ Examples of use for antigen exposure } & \multicolumn{1}{c}{ Reference } \\
\hline $\begin{array}{l}\text { Covalent bond formation between } \varepsilon \text {-amino } \\
\text { group of Lys and antigen containing free Cys } \\
\text { group with aid of cross-linking agent }\end{array}$ & $\begin{array}{l}\text { Diphtheria toxin, tumor necrosis factor (TNFo), model } \\
\text { vaccines against number of diseases, including rheuma- } \\
\text { toid arthritis, osteoporosis, autoimmune encephalitis, } \\
\text { myocarditis, hypertension, Alzheimer's disease, obesity, } \\
\text { atherosclerosis }\end{array}$ & [790] \\
\hline $\begin{array}{l}\text { His } 6 \text {-tag binding with antigen via trisNTA } \\
\text { molecule on VLP surface }\end{array}$ & $\begin{array}{l}\text { Model molecules including biotin, Alexa 488 (fluores- } \\
\text { cent dye), and GFP protein conjugated with trisNTA }\end{array}$ & [81, 87] \\
\hline $\begin{array}{l}\text { Isopeptide bond formation between SpyTag } \\
\text { (integrated into VLP monomers) and Spy- }\end{array}$ & $\begin{array}{l}\text { Vaccine against breast cancer (HER2 antigen presentation). } \\
\text { It is also implemented to develop vaccines against } \\
\text { malaria and tuberculosis }\end{array}$ & [82-86] \\
\hline
\end{tabular}

cessed by the same antigen-presenting cells simultaneously [90].

It should be noted that nanoprticle-based vaccines offer new possibilities in the development of immunoprophylaxis strategies, especially, the development of injection-free formulations, in particular, intranasal vaccines and inhalers. The administration of these vaccines may not involve humans, which is especially important in the case of industrial animal breeding in large agricultural enterprises characteristic of presentday Russia [19], since it proves to be extremely difficult to administer identical injections to a large number of animals at the same time. This problem may be resolved by nebulizing aerosol vaccines in the area where animals are kept. The potential of this approach was demonstrated for the first time in 1947 with mice [92]; then, in the 1950s-1970s, attempts were made to introduce this approach into animal and poultry farms in many countries. Starting from the 1960s, attempts were also made in the Soviet Union [93]. However, at that time, the method of inhaled administration of vaccines was not introduced in practice since protective immunity could only be obtained when the tolerable dose was exceeded many times. For example, the inhaled administration of the vaccine against the Newcastle disease led to $10-20 \%$ lethality in birds [94]. However, due to the introduction of vaccines based on the exposure of the epitopes of a pathogen on the surface of nanoparticles, including recombinant VLPs, together with the development of innovative approaches to aerosol production, inhaled vaccines again became a topical issue. For example, biodegradable polymer nanoparticles formed by poly(glyceroladipate-co- $\omega$-pentadecalactone), PGA-co-PDL, proved themselves as an effective antigen carrier for inhaled vaccination [95], while the vaccine based on the adenovirus with the particles ranging from 4 to $10 \mu \mathrm{m}$ induced stable protective immunity when administered via inhalation to monkeys [96]. Lastly, a method for VLP-vaccination via inhalation was proposed as protection against the human papilloma virus [97].
One of the most important properties of VLPs is mimicking virus particles and the consequent ability to induce a strong immune response to the antigen which they demonstrate irrespective of the source of the monomers which multimerize into VLPs, these being either insect viruses, in particular the gypsy virus [56, 61], or plant viruses [98]. VLPs based on the structural proteins of plant viruses produced in plants [99] make it possible to obtain vaccines with another nonconventional way of administration, edible vaccines [100]. Vaccines of this type may be synthesized directly in plant forage, with the oral vaccination of this kind inducing an immune response. Expression vectors for foreign protein production in plants have been developed based on plant viruses, which allows obtaining plant-producing recombinant viruses or VLPs displaying the target antigen on their surface [101, 102]. VLPs assembled from the structural proteins of plant viruses are also used to design functionalization platforms for antigen binding. These platforms are based on the strategies described above. In particular, they take advantage of the reactivity of the Lys $\varepsilon$-group to immobilize the antigen on the surface of the plant's VLPs [102-105]. Using the tobacco mosaic virus [106] and potato $X$ virus [104], it has been shown that a considerably large antigen can be immobilized on the surface of the corresponding VLPs via the formation of the streptavidin-biotin complex. Finally, based on the structural protein of the plant virus, the platform for antigen immobilization using the tag-catcher conjugation system is being developed [107]. It should be noted that among the drawbacks of VLP vaccines manufactured using proteins which are not specific for mammals, for example, the plant virus proteins, include the development of the immune response to the structural component of the particles, which is the plant virus protein. Undoubtedly, there is no therapeutical benefit in developing such immunity; however, whether there are adverse effects will be demonstrated by further studies. 
The use of VLPs for vaccination in medicine is becoming increasingly widespread. This point is reinforced by the list of clinical trials of VLP vaccines prepared by the United States National Institute of Health. Currently, more than hundred VLP vaccines, which are directed against human and avian influenza viruses, the Norwalk virus, norovirus, HIV-1, and the Chikungunya virus, the foot-and-mouth disease virus, as well as against melanoma, adenocarcinoma, papillomatoses, and cervical cancer, are undergoing clinical trials (http://clinicaltrials.gov/ct2/search/index). It may be expected that the variety of nanoparticle vaccines against different cancers and viral infections will grow steadily, and VLPs which can be used for immunization against microorganisms belonging to different taxons as well helminthes will also be developed.

\section{ACKNOWLEDGMENTS}

We thank the designers Oleg Vasil'ev and Galina Podzolkova (Institute for Statistical Studies and Economics of Knowledge (ISSEK), National Research University Higher School of Economics) for their assistance in preparing the illustrations.

\section{FUNDING}

The article was prepared within the framework of the Basic Research Program at the National Research University Higher School of Economics (HSE) and supported within the framework of a subsidy by the Russian Academic Excellence Project 5-100.

\section{COMPLIANCE WITH ETHICAL STANDARDS}

The authors declare that they have no conflict of interest. This article does not contain any studies involving animals or human participants performed by any of the authors.

\section{REFERENCES}

1. Lu Y., Chan W., Ko B.Y., Van Lang C.C., Swartz J.R. 2015. Assessing sequence plasticity of a virus-like nanoparticle by evolution toward a versatile scaffold for vaccines and drug delivery. Proc. Natl. Acad. Sci. U. S. A. 112, 12360-12365.

2. Ho S.C., Yang Y. 2014. Identifying and engineering promoters for high level and sustainable therapeutic recombinant protein production in cultured mammalian cells. Biotechnol. Lett. 36, 1569-1579.

3. Mandl J.N., Schneider C., Schneider D.S., Baker M.L. 2018. Going to bat(s) for studies of disease tolerance. Front. Immunol. 9, 2112. https://doi.org/10.3389/fimmu.2018.02112

4. Zhang S., Yong L.K., Li D., Cubas R., Chen C., Yao Q. 2013. Mesothelin virus-like particle immunization controls pancreatic cancer growth through CD8+ T cell induction and reduction in the frequency of $\mathrm{CD} 4+$ foxp3+ ICOS- regulatory T cells. PLoS One. 8, e68303. https://doi.org/10.1371/journal.pone.0068303

5. Domingo E., Perales C. 2018. Quasispecies and virus. EurBiophys J. 47, 443-457.

6. Contreras M., Villar M., Alberdi P., de la Fuente J. 2016. Vaccinomics approach to tick vaccine development. Methods Mol. Biol. 1404, 275-286.

7. De Groot A.S. 2004. Immunome-derived vaccines. Exp. Opin. Biol. Ther. 4, 767-772.

8. Fiser A., Sali A. 2003. Modeller: Generation and refinement of homology-based protein structure models. Methods Enzymol. 374, 461-491.

9. Zhang Y. 2007. Template-based modeling and free modeling by I-TASSER in CASP7. Proteins. 69 (Suppl. 8), 108-117.

10. Reber H. 1973. Proceedings: basic considerations on the requirements to be met by disinfection procedures: The Swiss model. Zbl. Bakteriol. Orig. B. 157, 478-494.

11. Lambert C., Léonard N., De Bolle X., Depiereux E. 2002. ESyPred3D: Prediction of proteins 3D structures. Bioinformatics. 18, 1250-1256.

12. Bates P.A., Kelley L.A., MacCallum R.M., Sternberg M.J. 2001. Enhancement of protein modeling by human intervention in applying the automatic programs 3D-JIGSAW and 3D-PSSM. Proteins.5, 39-46.

13. Bennett-Lovsey R.M., Herbert A.D., Sternberg M.J., Kelley L.A. 2008. Exploring the extremes of sequence/structure space with ensemble fold recognition in the program Phyre. Proteins. 70, 611-625.

14. Lund O., Frimand K., Gorodkin J., Bohr H., Bohr J., Hansen J., Brunak S. 1997. Protein distance constraints predicted by neural networks and probability density functions. Protein Eng. 10, 1241-1248.

15. Guo J.T., Ellrott K., Xu Y. 2008. A historical perspective of template-based protein structure prediction. Methods Mol. Biol. 413, 3-42.

16. Qian B., Raman S., Das R., Bradley P., McCoy A.J., Read R.J., Baker D. 2007. High-resolution structure prediction and the crystallographic phase problem. Nature. 450, 259-264.

17. Zhang Y, Skolnick J. 2004. Scoring function for automated assessment of protein structure template quality. Proteins. 57, 702-710.

18. Crooks E.T., Moore P.L., Franti M., Cayanan C.S., Zhu P., Jiang P., de Vries R.P., Wiley C., Zharkikh I., Schülke N., Roux K.H., Montefiori D.C., Burton D.R., Binley J.M. 2007. A comparative immunogenicity study of HIV-1 virus-like particles bearing various forms of envelope proteins, particles bearing no envelope and soluble monomeric gp120. Virology. 366, 245-262.

19. Medina-Ramírez M., Sanders R.W., Sattentau Q.J. 2017. Stabilized HIV-1 envelope glycoprotein trimers for vaccine use. Curr. Opin. HIV AIDS. 12, 241-249.

20. Maegawa K., Shibata T., Yamaguchi R., Hiroike K., Izzati U.Z., Kuroda K., Sugita S., Kawasaki K., Nerome R., Nerome K. 2018. Overexpression of a virus-like particle influenza vaccine in Eri silkworm pupae, using Autographa californica nuclear polyhedrosis virus and host-range expansion. Arch. Virol. 163, 2787-2797. 
21. Ding X., Liu D., Booth G., Gao W., Lu Y. 2018. Viruslike particle engineering: from rational design to versatile applications. Biotechnol. J. 13, e1700324. https://doi.org/10.1002/biot.201700324

22. Elliott S.L., Suhrbier A., Miles J.J., Lawrence G., Pye S.J., Le T.T., Rosenstengel A., Nguyen T., Allworth A., Burrows S.R., Cox J., Pye D., Moss D.J., Bharadwaj M. 2008. Phase I trial of a CD8+ T cell peptide epitopebased vaccine for infectious mononucleosis. J. Virol. 82, 1448-1457.

23. Madera R., Gong W., Wang L., Burakova Y., Lleellish K., Galliher-Beckley A., Nietfeld J., Henningson J., Jia K., Li P., Bai J., Schlup J., McVey S., Tu C., Shi J. 2016. Pigs immunized with a novel E2 subunit vaccine are protected from subgenotype heterologous classical swine fever virus challenge. BMC Vet. Res. 12 (1), 197. https://doi.org/10.1186/s12917-016-0823-4

24. Ahmed K.S., Hussein S.A., Ali A.H., Korma S.A., Lipeng Q., Jinghua C. 2018. Liposome: Composition, characterisation, preparation, and recent innovation in clinical applications. J. Drug Target. 1-20. https://doi.org/10.1080/1061186X.2018.1527337

25. Gregory A.E., Titball R., Williamson D. 2013. Vaccine delivery using nanoparticles. Front. Cell. Infect. Microbiol. 3, 13. https://doi.org/10.3389/fcimb.2013.00013

26. Mustafaeva Z. 2016. Polymers in vaccine formulation. Sigma J. Eng. Nat. Sci. 34, 439-451.

27. Wang X., Cao F., Yan M., Liu Y., Zhu X., Sun H., Ma G. 2019. Alum-functionalized graphene oxide nanocomplexes for effective anticancer vaccination. Acta Biomater. 83, 390-399.

28. Fadel T.R., Fahmy T.M. 2014. Immunotherapy applications of carbon nanotubes: From design to safe applications. Trends Biotechnol. 32, 198-209.

29. Chackerian B., Frietze K.M. 2016. Moving towards a new class of vaccines for non-infectious chronic diseases. Expert. Rev. Vaccines. 15, 561-563.

30. Bachmann M.F., Jennings G.T. 2010. Vaccine delivery: A matter of size, geometry, kinetics and molecular patterns. Nat. Rev. Immunol. 10, 787-796.

31. Mohsen M.O., Gomes A.C., Vogel M., Bachmann M.F. 2018. Interaction of viral capsid-derived virus-like particles (VLPs) with the innate immune system. Vaccines (Basel). 6, pii: E37. https://doi.org/10.3390/vaccines6030037

32. Moraes A.M., Jorge S.A., Astray R.M., Suazo C.A., CalderónRiquelme C.E., Augusto E.F., Tonso A., Pamboukian M.M., Piccoli R.A., Barral M.F., Pereira C.A. 2012. Drosophila melanogaster S2 cells for expression of heterologous genes: From gene cloning to bioprocess development. Biotechnol. Adv. 30, 613-628.

33. Syomin B.V, Pelisson A., Ilyin Y.V, Bucheton A. 2004. Expression of the retrovirus Gypsy Gag in Spodopterafrugiperda cell culture with the recombinant baculovirus. Dokl. Biochem. Biophys. 398, 310-312.

34. Ren J., Bell G., Coy D.H., Brunicardi F.C. 1997. Activation of human somatostatin receptor type 2 causes inhibition of cell growth in transfected HEK293 but not in transfected CHO cells. J. Surg. Res. 71, 13-18.

35. Li K., Zhong B. 2018. Regulation of cellular antiviral signaling by modifications of ubiquitin and ubiquitin- like molecules. Immune Netw. 18, e4. https://doi.org/10.4110/in.2018.18.e4

36. Masavuli M.G., Wijesundara D.K., Torresi J., Gowans E.J., Grubor-Bauk B. 2017. Preclinical development and production of virus-like particles as vaccine candidates for hepatitis C. Front. Microbiol. 8, 2413. https://doi.org/10.3389/fmicb.2017.02413

37. Godi A., Bissett S.L., Miller E., Beddows S. 2015. Relationship between humoral immune responses against HPV16, HPV18, HPV31 and HPV45 in 12-15 year old girls receiving Cervarix ${ }^{\circledR}$ or Gardasil ${ }^{\circledR}$ Vaccine. PLoS One. 10, e0140926.

https://doi.org/10.1371/journal.pone.0140926

38. Rustandi R.R., Wang F., Hamm C., Cuciniello J.J., Marley M.L. 2014. Development of imaged capillary isoelectric focusing method and use of capillary zone electrophoresis in hepatitis $\mathrm{B}$ vaccine RECOMBIVAX $\mathrm{HB}^{\circledR}$. Electrophoresis. 35, 1072-1078.

39. Shen C., Ku Z., Zhou Y., Li D., Wang L., Lan K., Liu Q., Huang Z. 2016. Virus-like particle-based vaccine against coxsackievirus A6 protects mice against lethal infections. Vaccine. 34, 4025-4031.

40. Zheng X., Wang S., Zhang W., Liu X., Yi Y., Yang S., Xia X., Li Y., Zhang Z. 2016. Development of a VLPbased vaccine in silkworm pupae against rabbit hemorrhagic disease virus. Int. Immunopharmacol. 40, 164169.

41. Pan Q., He K., Huang K. 2008. Development of recombinant porcine parvovirus-like particles as an antigen carrier formed by the hybrid VP2 protein carrying immunoreactive epitope of porcine circovirus type 2 . Vaccine. 26, 2119-2126.

42. Patterson R., Eley T., Browne C., Martineau H.M., Werling D. 2015. Oral application of freeze-dried yeast particles expressing the PCV2b Cap protein on their surface induce protection to subsequent PCV2b challenge in vivo. Vaccine. 33, 6199-6205.

43. Zhang H., Qian P., Liu L., Qian S., Chen H., Li X. 2014. Virus-like particles of chimeric recombinant porcine circovirus type 2 as antigen vehicle carrying foreign epitopes. Viruses. 6, 4839-4855.

44. Li P.C., Qiao X.W., Zheng Q.S., Hou J.B. 2016. Immunogenicity and immunoprotection of porcine circovirus type 2 (PCV2) Cap protein displayed by Lactococcus lactis. Vaccine. 34, 696-702.

45. Xiao Y., Chen H.Y., Wang Y., Yin B., Lv C., Mo X., Yan H., Xuan Y., Huang Y., Pang W., Li X., Yuan Y.A., Tian K. 2016. Large-scale production of foot-andmouth disease virus (serotype Asia1) VLP vaccine in Escherichia coli and protection potency evaluation in cattle. BMC Biotechnol. 16 (1), 56. https://doi.org/10.1186/s12896-016-0285-6

46. Wang A., Gu L., Wu S., Zhu S. 2018. Duck hepatitis A virus structural proteins expressed in insect cells selfassemble into virus-like particles with strong immunogenicity in ducklings. Vet. Microbiol. 215, 23-28.

47. Syomin B.V., Leonova O.G., Trendeleva T.A., Zviagil'skaia R.A., Ilyin Y.V., Popenko V.I. 2012. Effect of nucleocapsid on multimerization of gypsy structural protein Gag. Mol. Biol. (Moscow). 46, 270-278. 
48. Dong Y., Cai J., Chen H., Chen L. 2016. Protection of a novel epitope-RNA VLP double-effective VLP vaccine. Antiviral Res. 134, 108-116.

49. Zhou Y., He C., Wang L., Ge B. 2017. Post-translational regulation of antiviral innate signaling. Eur. $J$. Immunol. 47, 1414-1426.

50. Panda S.K., Kapur N., Paliwal D., Durgapal H. 2015. Recombinant hepatitis E virus like particles can function as RNA nanocarriers. J. Nanobiotechnol. 13, 44. https://doi.org/10.1186/s12951-015-0101-9

51. Voronkova T., Kazaks A., Ose V., Scherneck S., Pumpens P., Ulrich R. 2007. Hamster polyomavirusderived virus-like particles are able to transfer in vitro encapsidated plasmid DNA to mammalian cells. Virus Genes. 34, 303-314.

52. Kimchi-Sarfaty C., Arora M., Sandalon Z., Oppenheim A., Gottesman M.M. 2003. High cloning capacity of in vitro packaged SV40 vectors with no SV40 virus sequences. Hum. Gene Ther. 14, 167-177.

53. Barr S.M., Keck K., Aposhian H.V. 1979. Cell-free assembly of a polyoma-like particlefrom empty capside and DNA. Virology. 96, 656-659.

54. Touzé A., Bousarghin L., Ster C., Combita A.L., Roingeard P., Coursaget P. 2001. Gene transfer using human polyomavirus BK virus-like particles expressed in insect cells. J. Gen. Virol. 82, 3005-3009.

55. Syomin B.V., Ivanova L.A., Popenko V.I., Ilyin Y.V. 2011. The structural protein Gag of the gypsy retrovirus forms virus-like particles in the bacterial cell. Mol. Biol. (Moscow). 45, 472-478.

56. Bush D.L., Vogt V.M. 2014. In vitro assembly of retroviruses. Annu. Rev. Virol. 1, 561-580.

57. Strods A., Ose V., Bogans J., Cielens I., Kalnins G., Radovica I., Kazaks A., Pumpens P., Renhofa R. 2015. Preparation by alkaline treatment and detailed characterisation of empty hepatitis B virus core particles for vaccine and gene therapy applications. Sci. Rep. 5, 11639. https://doi.org/10.1038/srep11639

58. Sarkar K., Sadhukhan S., Han S.S., Vyas Y.M. 2015. SUMOylation-disrupting WAS mutation converts WASp from a transcriptional activator to a repressor of NF- $\mathrm{KB}$ response genes in T cells. Blood. 126, 16701682.

59. Syomin B.V., Malikova M.A., Stepanov A.S, Ilyin Y.V. 2002. Homologous and heterologous type 2 casein kinases have the same effect on the affinity for RNA of the Gag structural protein of gypsy (mdg4). Mol. Biol. (Moscow). 36, 28-29.

60. Melchior F. 2000. SUMO-nonclassical ubiquitin. Annu. Rev. Cell Dev. Biol. 16, 591-626.

61. Syomin B.V., Ilyin Y.V. 2004. The functional motifs that are revealed in the Gypsy gag amino acid sequence. Dokl. Biochem. Biophys. 398, 291-293.

62. Gottwein E., Kräusslich H.G. 2005. Analysis of human immunodeficiency virus type 1 Gag ubiquitination. J. Virol. 79, 9134-9144.

63. Jäger S., Cimermancic P., Gulbahce N., Johnson J.R., McGovern K.E., Clarke S.C., Shales M., Mercenne G., Pache L., Li K., Hernandez H., Jang G.M., Roth S.L., Akiva E., Marlett J., et al. 2011. Global landscape of HIV-human protein complexes. Nature. 481, 365-370.
64. Lee D.H., Lee S.H., Kim A.R., Quan F.S. 2016. Viruslike nanoparticle vaccine confers protection against Toxoplasma gondii. PLoS One. 11, e0161231. https://doi.org/10.1371/journal.pone.0161231

65. Pleckaityte M., Bremer C.M., Gedvilaite A., Kucinskaite-Kodze I., Glebe D., Zvirbliene A. 2015. Construction of polyomavirus-derived pseudotype virus-like particles displaying a functionally active neutralizing antibody against hepatitis B virus surface antigen. BMC Biotechnology. 15, 85. https://doi.org/10.1186/s12896-015-0203-3

66. Sominskaya I., Skrastina D., Dislers A., Vasiljev D., Mihailova M., Ose V., Dreilina D., Pumpens P. 2010. Construction and immunological evaluation of multivalent hepatitis B virus (HBV. core virus-like particles carrying HBV and HCV epitopes. Clin. Vaccine Immunol. 17, 1027-1033.

67. Mastico R.A., Talbot S.J., Stockley P.G. 1993. Multiple presentation of foreign peptides on the surface of an RNA-free spherical bacteriophage capsid. J. Gen. Virol. 74, 541-548.

68. Dong Y., Zhang G., Huang X.J., Chen L., Chen H.T. 2015. Promising MS2 mediated virus-like particle vaccine against foot-and-mouth disease. Antiviral Res. 117, 39-43.

69. Wong H.T., Cheng S.C., Chan E.W., Sheng Z.T., Yan W.Y., Zheng Z.X., Xie Y. 2000. Plasmids encoding foot-and-mouth disease virus VP1 epitopes elicited immune responses in mice and swine and protected swine against viral infection. Virology. 278, 27-35.

70. Chen W., Liu M., Jiao Y., Yan W., Wei X., Chen J., Fei L., Liu Y., Zuo X., Yang F., Lu Y., Zheng Z. 2006. Adenovirus-mediated RNA interference against foot-andmouth disease virus infection both in vitro and in vivo. J. Virol. 80, 3559-3566.

71. Shao J.J., Wong C.K., Lin T., Lee S.K., Cong G.Z., Sin F.W., Du J.Z., Gao S.D., Liu X.T., Cai X.P., Xie Y., Chang H.Y., Liu J.X. 2011. Promising multiple epitope recombinant vaccine against foot-and-mouth disease virus type $\mathrm{O}$ in swine. Clin. Vaccine Immunol. 18, 143-149.

72. Schwarz B., Madden P., Avera J., Gordon B., Larson K., Miettinen H.M., Uchida M., LaFrance B., Basu G., Rynda-Apple A., Douglas T. 2015. Symmetry controlled, genetic presentation of bioactive proteins on the p22 virus-like particle using an external decoration protein. ACS Nano. 9, 9134-9147.

73. Syomin B.V., Fedorova L.I., Surkov S.A., Ilyin Y.V. 2001. Drosophila melanogaster endogenous retrovirus gypsy can propagate in Drosophila hydei cells. Mol. Gen. Genet. 264, 588-594.

74. Syomin B.V., Popenko V.I., Malikova M.A., Stepanov A.S., Ilyin Y.V. 2001. Bacterially expressed polyprotein Gag of retroelement gypsy (MDG4) is able to form multimeric complexes. Dokl. Biochem. Biophys. 380, 322-324.

75. Syomin B.V., Kandror K.V., Semakin A.B., Tsuprun V.L., Stepanov A.S. 1993. Presence of gypsy (mdg4) retrotransposon in the extracellular virus like particles. FEBS Lett. 323, 285-288.

76. Syomin B.V., Samuilenko A.Ya. 2017. A novel strategy of veterinary vaccines production conditioned by the development of vaccinomics. Epizootol. Immunobiol. Farmakol. 1, 48-56. 
77. Dorn D.C., Lawatscheck R., Zvirbliene A., Aleksaite E., Pecher G., Sasnauskas K., Ozel M., Raftery M., Schönrich G., Ulrich R.G., Gedvilaite A. 2008. Cellular and humoral immunogenicity of hamster polyoma virus-derived virus-like particles harboring a mucin 1 cytotoxic T-cell epitope. Viral Immunol. 21, 12-27.

78. Smith M.T., Hawes A.K., Bundy B.C. 2013. Reengineering viruses and virus-like particles through chemical functionalization strategies. Curr. Opin. Biotechnol. 24, 620-626.

79. Sapsford K.E., Algar W.R., Berti L., Gemmill K.B., Casey B.J., Oh E., Stewart M.H., Medintz I.L. 2013. Functionalizing nanoparticles with biological molecules: Developing chemistries that facilitate nanotechnology. Chem. Rev. 113, 1904-2074.

80. Jennings G.T., Bachmann M.F. 2009. Immunodrugs: Therapeutic VLP-based vaccines for chronic diseases. Annu. Rev. Pharmacol. Toxicol. 49, 303-326. https://doi.org/10.1146/annurev-pharmtox-061008-103129

81. Koho T., Ihalainen T.O., Stark M., Uusi-Kerttula H., Wieneke R., Rahikainen R., Blazevic V., Marjomäki V., Tampé R., Kulomaa M.S., Hytönen V.P. 2015. Histagged norovirus-like particles: A versatile platform for cellular delivery and surface display. Eur. J. Pharm. Biopharm. 96, 22-31. https://doi.org/10.1016/j.ejpb.2015.07.002

82. Jegerlehner A., Tissot A., Lechner F., Sebbel P., Erdmann I., Kündig T., Bächi T., Storni T., Jennings G., Pumpens P., Renner W.A., Bachmann M.F. 2002. A molecular assembly system that renders antigens of choice highly repetitive for induction of protective $B$ cell responses. Vaccine. 20, 3104-3112.

83. Thrane S., Janitzek C.M., Matondo S., Resende M., Gustavsson T., de Jongh W.A., Clemmensen S., Roeffen W., van de Vegte-Bolmer M., van Gemert G.J., Sauerwein R., Schiller J.T., Nielsen M.A., Theander T.G., Salanti A., Sander A.F. 2016. Bacterial superglue enables easy development of efficient virus-like particle based vaccines. J. Nanobiotechnol. 14, 30. https://doi.org/10.1186/s12951-016-0181-1

84. Zakeri B., Fierer J.O., Celik E., Chittock E.C., Schwarz-Linek U., Moy V.T., Howarth M. 2012. Peptide tag forming a rapid covalent bond to a protein, through engineering a bacterial adhesin. Proc. Natl. Acad. Sci. U. S. A. 109 (12), E690-E697. https://doi.org/10.1073/pnas.1115485109

85. Singh S.K., Thrane S., Janitzek C.M., Nielsen M.A., Theander T.G., Theisen M., Salanti A., Sander A.F. 2017. Improving the malaria transmission-blocking activity of a Plasmodium falciparum $48 / 45$ based vaccine antigen by SpyTag/SpyCatcher mediated viruslike display. Vaccine. 35 (30), 3726-3732.

86. Palladini A., Thrane S., Janitzek C.M., Pihl J., Clemmensen S.B., de Jongh W.A, Clausen T.M., Nicoletti G., Landuzzi L., Penichet M.L., Balboni T., Ianzano M.L., Giusti V., Theander T.G., Nielsen M.A., et al. 2018. Virus-like particle display of HER2 induces potent anti-cancer responses. Oncoimmunology. 7 (3), e1408749. https://doi.org/10.1080/2162402X.2017.1408749

87. Xie J., Li K., Gao Y., Huang R., Lai Y., Shi Y., Yang S., Zhu G., Zhang Q., He J. 2016. Structural analysis and insertion study reveal the ideal sites for surface display- ing foreign peptides on a betanodavirus-like particle. Vet. Res. 47, 16.

https://doi.org/10.1186/s13567-015-0294-9

88. Wu T., Li S.W., Zhang J., Ng M.H., Xia N.S., Zhao Q. 2012. Hepatitis E vaccine development: A 14 year odyssey. Hum. Vaccin. Immunother. 8, 823-827.

89. Vandoolaeghe P., Schuerman L. 2016. The RTS, S/AS01 malaria vaccine in children 5 to 17 months of age at first vaccination. Expert Rev. Vaccines. 15, 14811493.

90. Mohsen M.O., Gomes A.C., Cabral-Miranda G., Krueger C.C., Leoratti F.M., Stein J.V., Bachmann M.F. 2017. Delivering adjuvants and antigens in separate nanoparticles eliminates the need of physical linkage for effective vaccination. J. Control. Release. 251, 92100.

91. Dranev Y., Kotsemir M., Syomin B. 2018. Diversity of research publications: Relation to agricultural productivity and possible implications for STI policy. Scientometrics. 116, 1565-1587.

92. Bryson V., Swanstrom M. 1947. Immunization of mice against pneumococcal pneumonia by inhaled polysaccharide. J. Bacteriol. 54, 87.

93. Pisarevskii Yu.S. 1963. Anatomical and physiological features of the human and animal respiratory system in the genesis of immunity after aerosol vaccination: 1. Role of airway structure in mechanical retention of inhyaled material. Zh. Mikrobiol. Epidemiol. Immunobiol. 40, 57-61.

94. Fournier J.M., Gaudry D., Moreau Y., Balençon, Fontanges R. 2076. Dry aerosol vaccination against Newcastle disease: 1. Safety and activity controls on chickens. Dev. Biol. Stand. 33, 269-272.

95. Kunda N.K., Alfagih I.M., Dennison S.R., Tawfeek H.M., Somavarapu S., Hutcheon G.A., Saleem I.Y. 2015. Bovine serum albumin adsorbed PGA-co-PDL nanocarriers for vaccine delivery via dry powder inhalation. Pharmacol. Res. 32, 1341-1353.

96. Bolton D.L., Song K., Tomaras G.D., Rao S., Roederer M. 2017. Unique cellular and humoral immunogenicity profiles generated by aerosol, intranasal, or parenteral vaccination in rhesus macaques. Vaccine. 35, 639-646.

97. Ilic V., Dunet V., Le Pape A., Buchs M., Kosinski M., Bischof Delaloye A., Gerber S., Prior J.O. 2016. SPECT/CT study of bronchial deposition of inhaled particles. A human aerosol vaccination model against HPV. Nuklearmedizin. 55, 203-208.

98. Bachmann M.F., Zabel F. 2016. Immunology of viruslike particles. In: Viral Nanotechnology. Eds. Khudyakov Y.E., Pumpens P. Boca Raton, CRC Press. pp. $121-128$.

99. Shirbaghaee Z., Bolhassani A. 2016. Different applications of virus-like particles in biology and medicine: Vaccination and delivery systems. Biopolymers. 105, $113-132$. https://doi.org/10.1002/bip.22759

100. Wesołowska A., Kozak Ljunggren M., Jedlina L., Basałaj K., Legocki A., Wedrychowicz H., Kesik-Brodacka M. 2018. A preliminary study of a lettuce-based edible vaccine expressing the cysteine proteinase of Fasciola hepatica for fasciolosis control in livestock. 
Front. Immunol. 9, 2592.

https://doi.org/10.3389/fimmu.2018.02592

101. Musiychuk K., Stephenson N., Bi H., Farrance C.E., Orozovic G., Brodelius M., Brodelius P., Horsey A., Ugulava N., Shamloul A.M., Mett V., Rabindran S., Streatfield S.J., Yusibov V. 2006. A launch vector for the production of vaccine antigens in plants. Influenza Other Respir. Viruses. 1, 19-25.

102. O’Brien G.J., Bryant C.J., Voogd C., Greenberg H.B., Gardner R.C., Bellamy A.R. 2000. Rotavirus VP6 expressed by PVX vectors in Nicotiana benthamiana coats PVX rods and also assembles into virus-like particles. Virology. 270, 444-453.

103. McCormick A.A., Corbo T.A., Wykoff-Clary S., Palmer K.E., Pogue G.P. 2006. Chemical conjugate TMV-peptide bivalent fusion vaccines improve cellular immunity and tumor protection. Bioconjug. Chem. 17, 1330-1338.

104. Steinmetz N.F., Mertens M.E., Taurog R.E., Johnson J.E., Commandeur U., Fischer R., Manchester M. 2010.
Potato virus $\mathrm{X}$ as a novel platform for potential biomedical applications. Nano Lett. 10, 305-312.

105. Zeltins A., West J., Zabel F., El Turabi A., Balke I., Haas S., Maudrich M., Storni F., Engeroff P., Jennings G.T., Kotecha A., Stuart D.I., Foerster J., Bachmann M.F. 2017. Incorporation of Tetanus-epitope into virus-like particles achieves vaccine responses even in older recipients in models of psoriasis, Alzheimer's and cat allergy. NPJ Vaccines. 2, 30. https://doi.org/10.1038/s41541-017-0030-8

106. Smith M.L., Lindbo J.A., Dillard-Telm S., Brosio P.M., Lasnik A.B., McCormick A.A., Nguyen L.V., Palmer K.E. 2006. Modified tobacco mosaic virus particles as scaffolds for display of protein antigens for vaccine applications. Virology. 348, 475-788.

107. Balke I., Zeltins A. 2018. Use of plant viruses and virus-like particles for the creation of novel vaccines. Adv. Drug Deliv. Rev. pii: S0169-409X(18)30204-7. https://doi.org/10.1016/j.addr.2018.08.007

Translated by E. Martynova 